\title{
Performance Analysis of DTC-SVM Sliding Mode Controllers-Based Parameters Estimator of Electric Motor Speed Drive
}

\author{
Fatma Ben Salem and Nabil Derbel \\ Control \& Energy Management Laboratory (CEMLab), Sfax Engineering School, University of Sfax, BP 1173, 3038 Sfax, Tunisia \\ Correspondence should be addressed to Fatma Ben Salem; fatma_bs@yahoo.fr
}

Received 10 June 2014; Revised 14 August 2014; Accepted 19 August 2014; Published 11 September 2014

Academic Editor: Rongni Yang

Copyright (C) 2014 F. Ben Salem and N. Derbel. This is an open access article distributed under the Creative Commons Attribution License, which permits unrestricted use, distribution, and reproduction in any medium, provided the original work is properly cited.

\begin{abstract}
This paper is concerned with a framework which unifies direct torque control space vector modulation (DTC-SVM) and variable structure control (VSC). The result is a hybrid VSC-DTC-SVM controller design which eliminates several major limitations of the two individual controls and retains merits of both controllers. It has been shown that obtained control laws are very sensitive to variations of the stator resistance, the rotor resistance, and the mutual inductance. This paper discusses the performances of adaptive controllers of VSC-DTC-SVM monitored induction motor drive in a wide speed range and even in the presence of parameters uncertainties and mismatching disturbances. Better estimations of the stator resistance, the rotor resistance, and the mutual inductance yield improvements of induction motor performances using VSC-DTC-SVM, thereby facilitating torque ripple minimization. Simulation results verified the performances of the proposed approach.
\end{abstract}

\section{Introduction}

Many fascinating and challenging subjects of induction machine control have been developed in order to provide a fast dynamic response of torque and reduction of the complexity of field oriented algorithms. Among several approaches used to control induction motors (IM) is the direct torque control (DTC), which has significantly improved the drive performances when compared to the vector control. The DTC was first proposed by Takahashi and Noguchi and by Depenbrock et al. in the mid of $1980[1,2]$. In a direct torque controlled induction motor supplied by a voltage source inverter (VSI), it is possible to directly control the electromagnetic torque and the stator flux within the prefixed hysteresis band limits by the selection of optimum inverter voltage vector. The main advantages of DTC are minimal torque response time, absence of complex coordinate transformation, voltage or current modulator, and simpler implementation [3-7]. However, there are a few shortcomings to DTC strategy which in order to provide a high performance drive, it has to be addressed properly. In this regard, they are excessive torque and flux ripples $[3,8-$ 10] and uncontrolled switching frequency of the inverter inducing vibrations $[3,8,11]$.

Recently, many research efforts have been carried out to reduce the torque ripples and harmonics and to improve the uncontrolled commutation frequency. In fact, in order to reduce the level of torque and flux ripples, several researchers have proposed the use of multilevel inverters [1214], and others have focused on SVM based inverter switching technique [15-20]. The inverter switching frequency is ensured constantly by space voltage vector modulation. Then, it is possible to combine the advantages of space vector modulation with the advantages of the DTC strategy. In conventional DTC-SVM, PI controllers are used [18, 19]. PI controllers are more suitable in the steady state condition and for linear systems. But, since DTC-SVM along with IM is mostly nonlinear, sliding mode controllers will be more suitable. Sliding mode controllers perform well in nonlinear systems than PI controllers [21-23]. In fact, a sliding mode control which is a variable structure control is basically a robust control that gives high performances of a drive 
with parameter variations and load torque disturbances. The control is nonlinear and can be easily applied to linear and nonlinear plants [24-26].

It should also be noted that the stator resistance, the rotor resistance, and the mutual inductance changes can significantly degrade the performances of a DTC-SVM induction motor, since the stator resistance is required for stator flux estimation and the rotor resistance and the mutual inductance are required for torque estimation in the basic configuration of DTC-SVM. A lot of researches have proposed nonlinear control laws with parameter estimations [27-29]. Among them, the sliding mode control which has good performances and is insensitive to parametric variations [23].

Within this approach, this paper proposes a DTC-SVM scheme using sliding mode controllers-based parameters estimator for induction motor drives. The effects of the stator resistance, the rotor resistance, and the mutual inductance variations on performances of VSC-DTC-SVM drives are investigated. Moreover, the expected responses to such a variation in terms of electromagnetic torque, stator flux, and stator current are confirmed through simulation results. Sensitivities of the DTC-SVM to temperature variations, leading to stator and rotor resistances changes, and to variations on the magnetic permeability of the stator and rotor cores, are eliminated by online estimation of stator and rotor resistances and mutual inductance. The proposed VSCDTC-SVM control algorithm based on parameters estimator is verified by simulation results.

While stochastic systems are very sensitive to external disturbances [30-33], it is to be noted that sliding mode controllers-based parameters estimator can be easily applied to linear and nonlinear deterministic and stochastic systems. In fact, sliding mode control is insensitive to external disturbances.

\section{Induction Motor and Voltage Source Inverter Models}

The dynamic behavior of an induction machine is described in terms of space variables as follows:

$$
\begin{gathered}
\frac{d}{d t} \phi_{\alpha s}=v_{\alpha s}-R_{s} i_{\alpha s}, \\
\frac{d}{d t} \phi_{\beta s}=v_{\beta s}-R_{s} i_{\beta s}, \\
\frac{d}{d t} \phi_{\alpha r}=-R_{r} i_{\alpha r}-\omega_{m} \phi_{\beta r}, \\
\frac{d}{d t} \phi_{\beta r}=-R_{r} i_{\beta r}+\omega_{m} \phi_{\alpha r},
\end{gathered}
$$

where subscripts $s$ and $r$ refer to stator and rotor, subscripts $\alpha$ and $\beta$ refer to components in $(\alpha, \beta)$ frame, $v, i$, and $\phi$ refer to voltage, current, and flux, $R_{s}$ and $R_{r}$ refer to stator and rotor resistances, and $\omega_{m}$ refers to the machine speed $\left(\omega_{m}=N_{p} \Omega_{m}=\omega_{s}-\omega_{r}\right.$ and $N_{p}$ is the pole pair number).
Relationships between currents and flux are

$$
\begin{aligned}
& \phi_{\alpha s}=L_{s} i_{\alpha s}+M i_{\alpha r}, \\
& \phi_{\alpha r}=M i_{\alpha s}+L_{r} i_{\alpha r}, \\
& \phi_{\beta r}=M i_{\beta s}+L_{r} i_{\beta r}, \\
& \phi_{\beta s}=L_{s} i_{\beta s}+M i_{\beta r},
\end{aligned}
$$

where $L$ and $M$ refer to the inductance and the mutual one.

The machine speed results from the following differential equation:

$$
J \frac{d}{d t} \Omega_{m}=T_{\mathrm{em}}-T_{r}
$$

where $T_{\mathrm{em}}$ is the electromagnetic torque and $T_{r}=K_{l} \Omega_{m}$ is the load torque. This yields the following transfer function:

$$
\frac{\Omega_{m}}{T_{\mathrm{em}}}=\frac{1}{K_{l}+J p} .
$$

In a voltage fed three phases, the switching commands of each inverter leg are complementary. So for each leg, a logic state $S_{i}(i=a, b, c)$ can be defined. $S_{i}$ is 1 if the upper switch is commanded to be closed and 0 if the lower one is commanded to be closed. There are six nonzero voltage vectors and two zero voltage ones $\left(S_{a}, S_{b}, S_{c}=000 / 111\right)$, which can be applied to the machine terminals.

The voltage vector of the three-phase voltage inverters is represented as follows:

$$
\bar{V}_{s}=\sqrt{\frac{2}{3}}\left[S_{a}+S_{b} e^{j(2 \pi / 3)}+S_{c} e^{j(4 \pi / 3)}\right] .
$$

\section{DTC-SVM Principles}

The DTC strategy is built upon the direct control of stator flux and electromagnetic torque through stator voltage vector selection. This strategy presents the advantage of a very simple control scheme of stator flux and torque by two hysteresis controllers, which give the input voltage of the motor by selecting the appropriate voltage vectors of the inverter through a look-up-table in order to keep stator flux and torque within the limits of two hysteresis bands.

The basic equation governing induction motor operation stator flux is given by

$$
\frac{d}{d t} \bar{\Phi}_{s}=\bar{V}_{s}-R_{s} \bar{I}_{s}
$$

where $\bar{\Phi}_{s}, \bar{V}_{s}, \bar{I}_{s}$, and $R_{s}$ are the stator flux, voltage, current, and resistance, respectively. If numerical time varying quantities are considered, and if the voltage drop across the stator resistance is neglected, (6) yields

$$
\Delta \bar{\Phi}_{s}=\bar{\Phi}_{s}\left([K+1] T_{s}\right)-\bar{\Phi}_{s}\left(K T_{s}\right) \simeq \bar{V}_{s} T_{s},
$$

where $T_{s}$ is the sampling period. This means that the direction of the flux variation is held by the voltage phasor. 
Electromagnetic torque in an induction motor is given by

$$
T_{\mathrm{em}}=N_{p} \frac{M}{L_{r} L_{s}-M^{2}}\left\|\Phi_{s}\right\|\left\|\Phi_{r}^{\prime}\right\| \sin \delta,
$$

where $\Phi_{r}^{\prime}$ is the rotor flux referred to the stator winding and $\delta$ is the angle between the stator and the rotor flux-linkage space vectors.

It can be concluded from (8) that an increment in torque can be achieved by increasing the angle between stator and rotor flux vector.

However, the basic DTC approach causes large torque and flux ripples, accompanied by acoustical noise, due to the uncontrolled switching frequency [3]. One way to decrease the ripples and to maintain a constant frequency is by the use of the space vector to modulation (SVM) $[18,20]$. The SVM technique refers to a special switching scheme of the six power transistors of a 3-phase PWM inverter. In fact, the SVM technique uses eight switching combinations to control the stator flux, and eight switching combinations, to approximate the circle flux reference and to reach higher control performances.

The direct torque control based on space vector modulation (DTC-SVM) preserves DTC transient merits, furthermore, it produces better quality of the steady state performances in a wide speed range [23]. At each period cycle ( $\left.T_{\text {mod }}\right)$, SVM technique is used to obtain the reference voltage space vector $\vec{V}_{s}^{*}$ to compensate the flux and the torque errors. For example, if the reference stator voltage vector is between vectors $\vec{V}_{2}$ (110) and $\vec{V}_{3}(010), \vec{V}_{2}, \vec{V}_{3}$, and zero voltage vectors, $\vec{V}_{0}(000)$ are selected. The method to calculate the time durations $\left(T_{1}, T_{2}\right.$ and $\left.T_{0}\right)$ corresponding to voltage vectors $\vec{V}_{2}, \vec{V}_{3}$ and $\vec{V}_{0}$, respectively, has been presented in $[19,23]$.

When this method is employed, the hysteresis controllers and the look-up tables present in DTC are replaced by PI controllers and a space vector modulator, thus achieving a fixed switching frequency and reducing considerably the switching losses as well as torque and current ripples.

The linear PI controllers and a space vector modulator are investigated by $[18,19,34]$. The hysteresis comparators of torque and flux are replaced by PI controllers. However, the main drawbacks of DTC-SVM using PI controllers are the sensitivity of the performances to the system-parameter variations and the inadequate rejection of external disturbances and load changes. In addition, it has been noted that a given voltage space vector has different effects on the drive behavior depending whether high or low speed operation is considered $[23,35]$. The sliding mode control is a type of variable structure system characterized by the high simplicity and the robustness against insensitivity to parameters variations and external disturbances. The dynamic of the system while in sliding mode is insensitive to model uncertainties and external disturbances. However, the major limitation of the individual variable structure control is the high-frequency switching [36]. DTC-SVM using sliding mode controllers seems as an effective solution to overcome these problems. They feature robustness to parameter variations, fast dynamic response, and simplicity of design and implementation.

\section{Variable Structure Control DTC-SVM Scheme}

Sliding mode (SM) control is well known as variable structure control (VSC) [21, 24, 37, 38]. Variable structure systems and their associated sliding regimes are characterized by discontinuous nature of the control action with a desired dynamic of the system which is obtained by an adequate choice of sliding surfaces. Control actions provide the switching between subsystems which give a desired behavior of the closed loop system. For example, consider a linear system described by the following transfer function:

$$
\frac{Y}{U}=\frac{b}{p^{n}+a_{n-1} p^{n-1}+\cdots+a_{1} p+a_{0}} .
$$

A choice of the state equation of this system is the following: $X=\left[Y, \dot{Y} \cdots Y^{(n-1)}\right]^{T}$.

The objectives of the sliding mode control consist of the following steps [37-39]:

(i) Design the switching function $S(X)$ in order to drive dynamics of the system to evolve on the sliding surface $S(X)=0$ in a reduced time and to remain on this surface. For $S(X) \neq 0$, the condition $S(X) \dot{S}(X)<$ 0 is required to achieve the convergence to the surface $S(X)=0$.

Then, a choice of the sliding surface $S(X)$ can be given by

$$
S(X)=\left(\frac{d^{n-1}}{d t^{n-1}}+\zeta_{n-2} \frac{d^{n-2}}{d t^{n-2}}+\cdots+\zeta_{1} \frac{d}{d t}+\zeta_{0}\right) \varepsilon,
$$

with $\varepsilon=Y-Y_{r}$ and $Y_{r}$ is a reference signal. It is to be noted that roots of the following polynomial must have negative real parts:

$$
p^{n-1}+\zeta_{n-2} p^{n-2}+\cdots+\zeta_{1} p+\zeta_{0}=0 .
$$

(ii) Determine a switching control strategy as

$$
U=U_{\mathrm{eq}}+\Delta U \text {. }
$$

In order to decide a system trajectory, the equivalent control $U_{\text {eq }}$ represents the required control to reach and to remain on the sliding surface. The corrected term $\Delta U$ is required to guarantee a stable system outside the sliding surface.

Thus, one can choose for the controller the following expression:

$$
\Delta U=-U_{0} \operatorname{sgn}[b S(X)],
$$

and the equivalent control can be designed as follows. When the system remains on the sliding surface, we have $S(X)=0$; then $\dot{S}(X)=0$. This yields the following expression of the equivalent control:

$$
U_{\mathrm{eq}}=\frac{1}{b}\left[\frac{d^{n} Y_{r}}{d t^{n}}+\sum_{i=0}^{n-1} a_{i} \frac{d^{i} Y}{d t^{i}}-\sum_{j=0}^{n-2} \zeta_{j} \frac{d^{j+1} \varepsilon}{d t^{j+1}}\right] .
$$




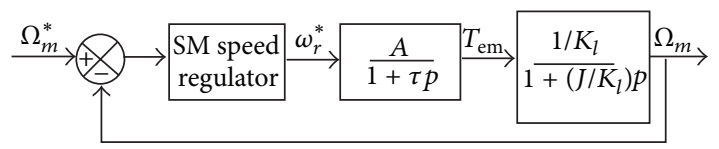

FIgURE 1: Sliding mode loop of the speed control.

4.1. Speed VSC Design. The proposed variable structure controllers will be designed to provide the fast and accurate torque and flux control laws which replace the traditional hysteresis comparators used in conventional DTC strategy. The sliding surface is chosen as

$$
S_{\Omega}=\lambda_{1}\left(\Omega_{m}-\Omega_{m}^{*}\right)+\frac{d}{d t}\left(\Omega_{m}-\Omega_{m}^{*}\right)
$$

where $\Omega_{m}^{*}$ is the desired speed. This choice takes into account that the error $\varepsilon=\Omega_{m}-\Omega_{m}^{*}$ decreases exponentially after reaching the sliding surface. In fact, if for $t \geq t_{0}$, we have $S_{\Omega}=\lambda_{1} \varepsilon+\dot{\varepsilon}=0$, then $\varepsilon=\varepsilon\left(t_{0}\right) e^{-\lambda_{1}\left(t-t_{0}\right)}$.

While the stator flux remains constant, it has been shown that the transmittance binding the torque $T_{\mathrm{em}}$ and the speed $\omega_{r}$ is given by $[9,19,23]$

$$
G(p)=\frac{T_{\mathrm{em}}}{\omega_{r}}=\frac{A}{1+\tau p},
$$

with $\tau=L_{r} / R_{r}$ and $A=N_{p}\left(M^{2} / R_{s} R_{r}\right)\left|\Phi_{r}^{*}\right|^{2}$.

Considering (4) and (16), the developed expression of the speed sliding surface is the following:

$$
S_{\Omega}=\left(\lambda_{1}-\frac{K_{l}}{J}\right) \Omega_{m}+\frac{T_{\mathrm{em}}}{J}-\lambda_{1} \Omega_{m}^{*}-\frac{d}{d t} \Omega_{m}^{*}
$$

In the sliding mode control $S_{\Omega}=0$, we have $\dot{S}_{\Omega}=0$. This gives the expression of the equivalent control as follows:

$$
\begin{aligned}
U_{\mathrm{eq}, 1}= & \frac{\tau K_{l}}{A}\left(\lambda_{1}-\frac{K_{l}}{J}\right) \Omega_{m}-\frac{\tau}{A}\left(\lambda_{1}-\frac{K_{l}}{J}-\frac{1}{\tau}\right) T_{\mathrm{em}} \\
& -\frac{J \tau}{A}\left(\lambda_{1} \dot{\Omega}_{m}^{*}+\ddot{\Omega}_{m}^{*}\right) .
\end{aligned}
$$

Then, the slip angular reference speed $\omega_{r}^{*}$ is expressed by

$$
\omega_{r}^{*}=U_{\mathrm{eq}, 1}-U_{0,1} \operatorname{sgn}\left(S_{\Omega}\right) .
$$

The SM control loop of the speed is presented in Figure 1.

Consider the following Lyapunov function:

$$
V_{\Omega}=\frac{1}{2} S_{\Omega}^{2}
$$

we have

$$
\dot{V}_{\Omega}=S_{\Omega} \dot{S}_{\Omega}=-S_{\Omega} \Delta U=-S_{\Omega} U_{0,1} \operatorname{sgn}\left(S_{\Omega}\right) .
$$

Then

$$
\dot{V}_{\Omega}=-U_{0,1}\left|S_{\Omega}\right| \leq 0 .
$$

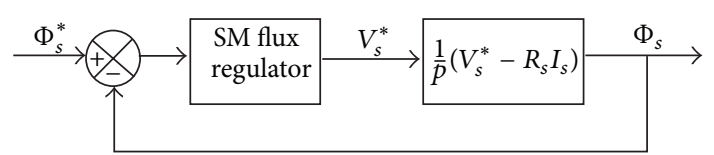

Figure 2: Sliding mode loop of the flux control.

4.2. Flux Reference Coordinates Computing. The slip angular reference speed $\omega_{r}^{*}$, which is the output of speed VSC controller, will be used to calculate the argument of the stator flux reference. The coordinates of the reference stator flux $\phi_{\alpha s}^{*}$ and $\phi_{\beta s}^{*}$ are computed according to the following expressions:

$$
\begin{aligned}
& \phi_{\alpha s}^{*}=\left|\Phi_{s}^{*}\right| \cos \theta_{s}^{*}, \\
& \phi_{\beta s}^{*}=\left|\Phi_{s}^{*}\right| \sin \theta_{s}^{*} .
\end{aligned}
$$

4.3. Flux VSC Design. The synthesis of the sliding mode controller of the stator flux consists of these following stages.

The choice of the sliding surface is given by (see Figure 2)

$$
S_{\phi}=\left(\Phi_{s}-\Phi_{s}^{*}\right)+\lambda_{2} \int\left(\Phi_{s}-\Phi_{s}^{*}\right) d t
$$

where $\Phi_{s}^{*}=\left|\Phi_{s}\right| e^{i \theta_{s}^{*}}$ and $\left|\Phi_{s}\right|=\Phi_{N}=1 \mathrm{~Wb}$.

Similarly to the last case, and imposing $S_{\phi}=0$ and then $\dot{S}_{\phi}=0$, the expression of the equivalent control is

$$
U_{\mathrm{eq}, 2}=R_{s} I_{s}+\dot{\Phi}_{s}^{*}-\lambda_{2}\left(\Phi_{s}-\Phi_{s}^{*}\right)
$$

This leads to the reference stator voltage control (Figure 2):

$$
V_{s}^{*}=U_{\mathrm{eq}, 2}-U_{0,2} \operatorname{sgn}\left(S_{\phi}\right) .
$$

The control law (26) stabilizes the closed loop subsystems described in Figure 2. In fact, considering the Lyapunov function

$$
V_{\phi}=\frac{1}{2} S_{\phi}^{T} S_{\phi}
$$

where

$$
S_{\phi}=\left[\begin{array}{c}
S_{\phi_{\alpha}} \\
S_{\phi_{\beta}}
\end{array}\right]
$$

we have

$$
\begin{aligned}
\dot{V}_{\phi} & =\frac{1}{2} S_{\phi}^{T} \dot{S}_{\phi}=S_{\phi_{\alpha}} \dot{S}_{\phi_{\alpha}}+S_{\phi_{\beta}} \dot{S}_{\phi_{\beta}} \\
& =-U_{0,2}\left(\left|S_{\phi_{\alpha}}\right|+\left|S_{\phi_{\beta}}\right|\right) \leq 0 .
\end{aligned}
$$

The new structure of this control approach is given by the block diagram of Figure 3.

\section{VSC-Based Parameters Estimation}

5.1. Mutual Inductance and Rotor Resistance Estimations. The sensitivity of the DTC-SVM to (i) variations on the 




FIGURE 3: Block diagram of DTC-SVM with sliding mode controllers.

magnetic permeability of the stator and rotor cores and (ii) variations on the rotor resistance, which can vary with time and operating conditions, can be removed by an online estimation of the mutual inductance and rotor resistance. The adaptive VSC of the speed can be derived based on the mutual inductance and rotor resistance estimations using the Lyapunov theorem.

Theorem 1. The following slip angular reference speed control law stabilizes the speed loop:

$$
\omega_{r}^{*}=\bar{U}_{e q, 1}-U_{0,1} \operatorname{sgn}\left(S_{\Omega}\right),
$$

where $\bar{U}_{e q, 1}=U_{e q, 1}\left(\bar{M}, \bar{R}_{r}\right), S_{\Omega}=\left(\lambda_{1}-K_{l} / J\right) \Omega_{m}+T_{e m} / J-$ $\lambda_{1} \Omega_{m}^{*}-\dot{\Omega}_{m}^{*}, \dot{S}_{\Omega}=\mathscr{A} \mathscr{X}+\mathscr{B} U, U_{e q}=-\mathscr{B}^{-1} \mathscr{A} \mathscr{X}, \mathscr{X}$ is a vector containing the machine state vector and the state vector of the reference trajectory, and $\bar{M}$ and $\bar{R}_{r}$ are estimator values of the mutual inductance and the rotor resistance given by the following updating laws:

$$
\begin{aligned}
& \dot{\bar{M}}=-\eta_{1} \overline{\mathscr{B}} S_{\Omega}\left(\frac{\partial U_{e q, 1}}{\partial M}\right)_{\left[\begin{array}{l}
M=\bar{M} \\
R_{r}=\bar{R}_{r}
\end{array}\right]}, \\
& \dot{\bar{R}}_{r}=-\eta_{2} \overline{\mathscr{B}} S_{\Omega}\left(\frac{\partial U_{e q, 1}}{\partial R}\right)_{\left[\begin{array}{l}
M=\bar{M} \\
R_{r}=\bar{R}_{r}
\end{array}\right]},
\end{aligned}
$$

with $\eta_{1}$ and $\eta_{2}$ are positive scalars, $\mathscr{B}=\mathscr{B}\left(M, R_{r}\right)$, and $\overline{\mathscr{B}}=$ $\overline{\mathscr{B}}\left(\bar{M}, \bar{R}_{r}\right)$.

Proof. Consider the following function:

$$
V_{\Omega}=\frac{1}{2} S_{\Omega}^{2}+\frac{1}{2 \eta_{1}} \Delta M^{2}+\frac{1}{2 \eta_{2}} \Delta R_{r}^{2},
$$

with $\Delta M=\bar{M}-M$ and $\Delta R_{r}=\bar{R}_{r}-R_{r}$.

The time derivative of the Lyapunov function can be expressed as

$$
\dot{V}_{\Omega}=S_{\Omega} \dot{S}_{\Omega}+\frac{1}{\eta_{1}} \Delta M \Delta \dot{M}+\frac{1}{\eta_{2}} \Delta R_{r} \Delta \dot{R}_{r}
$$

It is easy to show that $\dot{S}_{\Omega}$ is a linear function in terms of the control such that

$$
\dot{S}_{\Omega}=\mathscr{A} \mathscr{X}+\mathscr{B} U_{1}
$$

where

$$
U_{1}=\bar{U}_{\mathrm{eq}, 1}-U_{0,1} \operatorname{sgn}\left(S_{\Omega}\right)
$$

Then

$$
\begin{aligned}
\dot{S}_{\Omega} & =\mathscr{A} \mathscr{X}+\mathscr{B} \bar{U}_{\mathrm{eq}, 1}-U_{0,1} \operatorname{sgn}\left(S_{\Omega}\right) \\
& =\underbrace{\mathscr{A} \mathscr{X}+\mathscr{B} U_{\mathrm{eq}, 1}}_{=0}-U_{0,1} \operatorname{sgn}\left(S_{\Omega}\right)+\mathscr{B}\left(\bar{U}_{\mathrm{eq}, 1}-U_{\mathrm{eq}, 1}\right)
\end{aligned}
$$


or

$$
\begin{aligned}
\bar{U}_{\mathrm{eq}, 1} & -U_{\mathrm{eq}, 1} \\
= & (\bar{M}-M)\left(\frac{\partial U_{\mathrm{eq}, 1}}{\partial M}\right)_{\left[\begin{array}{l}
M=\bar{M} \\
R_{r} \bar{R}_{r}
\end{array}\right]} \\
& +\left(\bar{R}_{r}-R_{r}\right)\left(\frac{\partial U_{\mathrm{eq}, 1}}{\partial R_{r}}\right)_{\left[\begin{array}{l}
M=\bar{M} \\
R_{r}=\bar{R}_{r}
\end{array}\right]}+o\left(\Delta M, \Delta R_{r}\right)^{2} .
\end{aligned}
$$

Moreover

$$
\begin{aligned}
\mathscr{B} & \left(\bar{U}_{\text {eq }, 1}-U_{\text {eq }, 1}\right) \\
& =(\mathscr{B}-\overline{\mathscr{B}})\left(\bar{U}_{\text {eq }, 1}-U_{\text {eq }, 1}\right)+\overline{\mathscr{B}}\left(\bar{U}_{\text {eq }, 1}-U_{\text {eq }, 1}\right) \\
& =\overline{\mathscr{B}}\left(\bar{U}_{\text {eq }, 1}-U_{\text {eq }, 1}\right)+o\left(\Delta M, \Delta R_{r}\right)^{2} .
\end{aligned}
$$

In fact $\mathscr{B}-\overline{\mathscr{B}}=o\left(\Delta M, \Delta R_{r}\right)$ and $\bar{U}_{\text {eq, } 1}-U_{\text {eq, } 1}=o\left(\Delta M, \Delta R_{r}\right)$. Then $(\mathscr{B}-\overline{\mathscr{B}})\left(\bar{U}_{\text {eq }, 1}-U_{\text {eq } 11}\right)=o\left(\Delta M, \Delta R_{r}\right)^{2}$.

Thereby, (33) gives

$$
\begin{aligned}
\dot{V}_{\Omega}= & \Delta M \underbrace{\left[\overline{\mathscr{B}}\left(\frac{\partial U_{\mathrm{eq}, 1}}{\partial M}\right)_{\left[\begin{array}{l}
M=\bar{M} \\
R_{r}=\bar{R}_{r}
\end{array}\right]}+\frac{1}{\eta_{1}} \Delta \dot{M}\right]}_{=0} \\
& +\Delta R_{r} \underbrace{\left[\overline{\mathscr{B}}\left(\frac{\partial U_{\mathrm{eq}, 1}}{\partial R_{r}}\right)_{\left[\begin{array}{l}
M=\bar{M} \\
R_{r}=\bar{R}_{r}
\end{array}\right]}+\frac{1}{\eta_{1}} \Delta \dot{R}_{r}\right]}_{=0} \\
& -U_{0,1}\left|S_{\Omega}\right|+o\left(\Delta M, \Delta R_{r}\right)^{2}=-U_{0,1}\left|S_{\Omega}\right| \\
& +o\left(\Delta M, \Delta R_{r}\right)^{2} \leq 0 .
\end{aligned}
$$

Since $\dot{V}_{\Omega}$ is negative, the system is stable.

5.2. Stator Resistance Estimation. One of the main problems of the DTC of induction motor drives is the variation of the stator resistance, which could change up to 1.5-1.7 times of its nominal value. It is affected mainly by the change in motor temperature and stator frequency variation. This variation decreases the performances of the drive by introducing errors in the estimated magnitude and position of the stator flux vector [40]. For overcoming this problem, an online estimation of the stator resistance is proposed. In fact, the adaptive SM of the stator flux can be derived based on the stator resistance estimation using the Lyapunov theorem.

Theorem 2. The following stator voltage control laws stabilize the flux loop:

$$
\begin{gathered}
V_{\alpha s}^{*}=V_{\alpha s_{e q}}-k_{1} \operatorname{sgn}\left(S_{\phi_{\alpha}}\right), \\
V_{\beta s}^{*}=V_{\beta s_{e q}}-k_{2} \operatorname{sgn}\left(S_{\phi_{\beta}}\right),
\end{gathered}
$$

where

$$
\begin{aligned}
& V_{\alpha s_{e q}}=\bar{R}_{s} I_{\alpha s}-\omega_{s}^{*} \phi_{\beta s}^{*}-\lambda_{2} S_{\phi_{\alpha}}, \\
& V_{\beta s_{e q}}=\bar{R}_{s} I_{\beta s}+\omega_{s}^{*} \phi_{\alpha s}^{*}-\lambda_{2} S_{\phi_{\beta}},
\end{aligned}
$$

and $\bar{R}_{s}$ is the estimator value of the stator resistance, given by the following updating law:

$$
\dot{\bar{R}}_{s}=-\eta_{3}\left(S_{\phi_{\alpha}} I_{\alpha s}+S_{\phi_{\beta}} I_{\beta s}\right) \text {, }
$$

with $\eta_{3}$ being a positive scalar.

Proof. Considering the following function:

$$
V_{\phi}=\frac{1}{2} S_{\phi}^{T} S_{\phi}+\frac{1}{2 \eta_{3}} \Delta R_{s}^{2},
$$

with $\Delta R_{s}=\bar{R}_{s}-R_{s}$.

The time derivative of the Lyapunov function can be expressed as

$$
\begin{aligned}
\dot{V}_{\phi}= & -\lambda_{2}\left(S_{\phi_{\alpha}}\right)^{2}-\lambda_{2}\left(S_{\phi_{\beta}}\right)^{2}-k_{2}\left|S_{\phi_{\alpha}}\right|-k_{1}\left|S_{\phi_{\beta}}\right| \\
& +\underbrace{\left[\left(S_{\phi_{\alpha}} I_{\alpha s}+S_{\phi_{\beta}} I_{\beta s}\right)+\frac{1}{\eta_{2}} \Delta \dot{R}_{s}\right]}_{=0}+o\left(\Delta R_{s}\right)^{2} \\
= & -\lambda_{2}\left(S_{\phi_{\alpha}}\right)^{2}-\lambda_{2}\left(S_{\phi_{\beta}}\right)^{2}-k_{2}\left|S_{\phi_{\alpha}}\right|-k_{1}\left|S_{\phi_{\beta}}\right| \\
& +o\left(\Delta R_{s}\right)^{2} \leq 0 .
\end{aligned}
$$

Then the system is stable.

\section{Simulation Results and Discussions}

The induction motor has the following ratings: $220 \mathrm{~V}, 10 \mathrm{~kW}$, and $1470 \mathrm{rpm}$ at $50 \mathrm{~Hz}$. Its parameters are

$$
\begin{gathered}
R_{s}=0.29 \Omega, \quad R_{r}=0.38 \Omega, \quad J=0.5 \mathrm{Kg} \cdot \mathrm{m}^{2}, \\
L_{s}=L_{r}=50 \mathrm{mH}, \quad M=47.3 \mathrm{mH}, \quad p=2 .
\end{gathered}
$$

The above induction motor parameters have been determined from stator resistance measurement, no load test and blocked rotor test of an induction motor [41] of a test bench in the electric laboratory of the University of Sfax.

The induction motor is coupled to a load whose torque is proportional to the speed, such that $T_{r}=K_{l} \Omega_{m}$, where $K_{r}=$ $0.4053 \mathrm{Nms}$.

The rotor flux reference was constant, $\Phi_{s}=1 \mathrm{~Wb}$. The modulation period is fixed to $T_{\bmod }=150 \mu \mathrm{s}$ in DTC-SVM approach under study. 


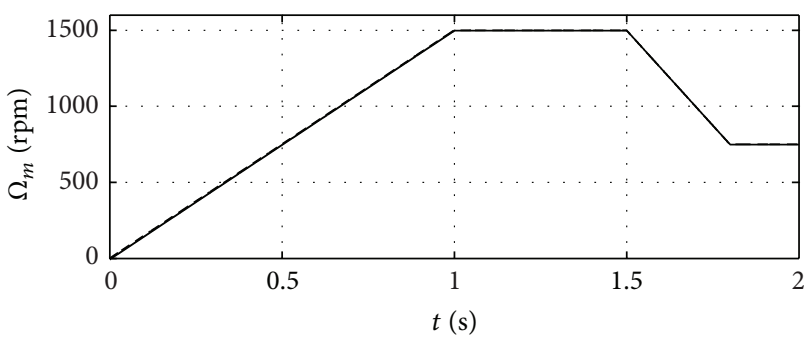

(a)

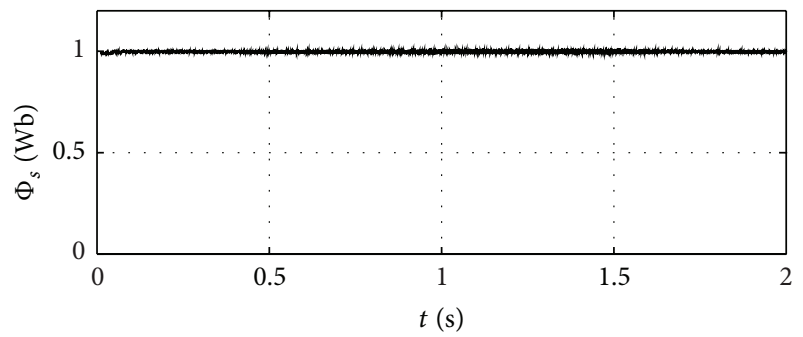

(c)

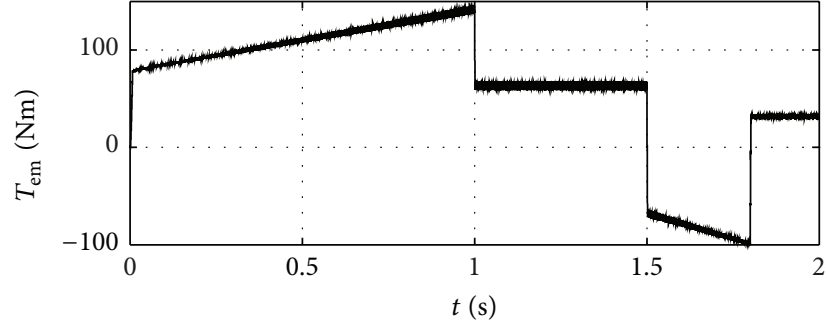

(b)

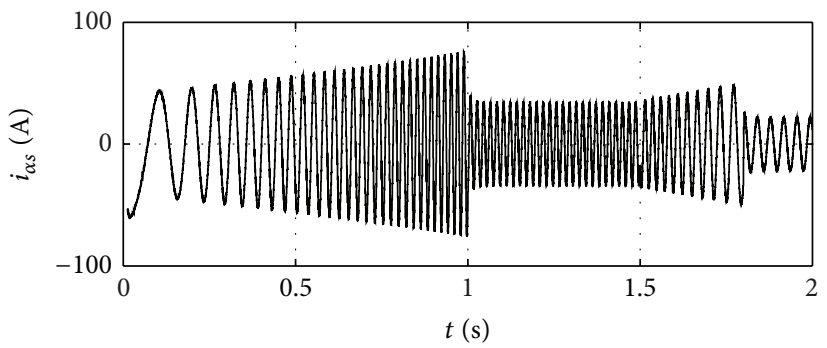

(d)

FIGURE 4: Transient behavior of the induction motor under DTC-SVM using sliding mode controllers, without parameters variations.

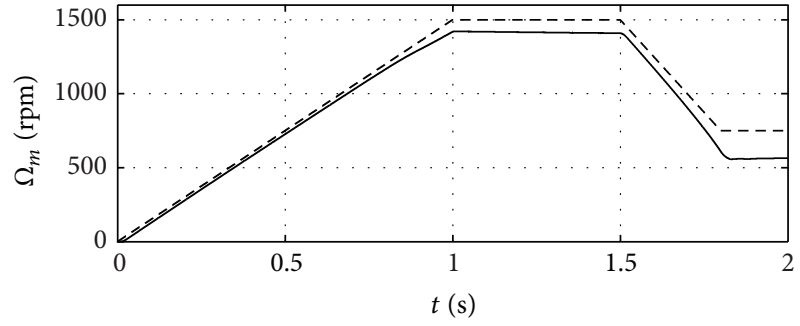

(a)



(c)

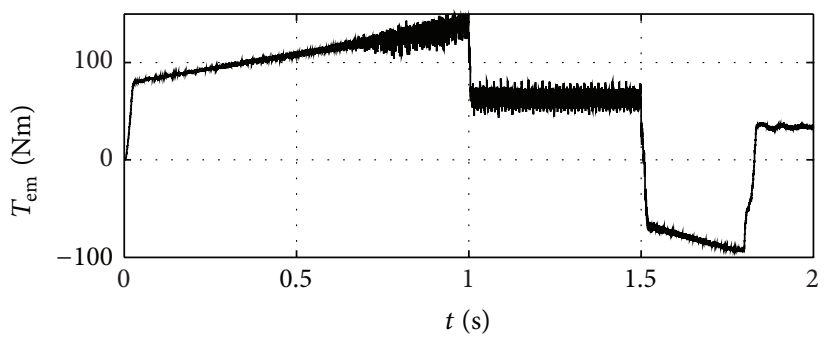

(b)

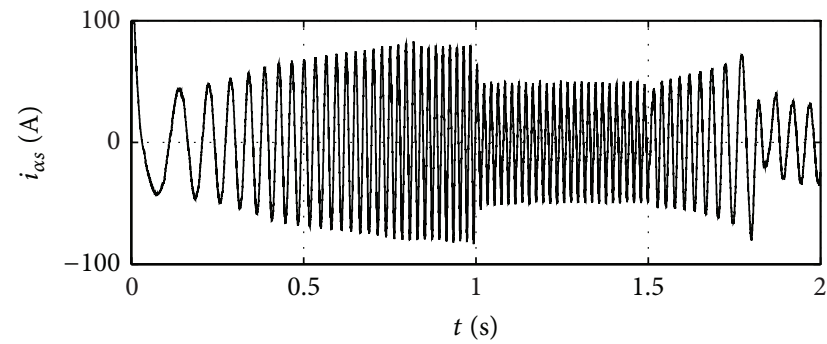

(d)

FIgURE 5: Transient behavior of the induction motor under DTC-SVM using sliding mode controllers without parameters estimation, with parameters variations $\Delta R_{s}=+100 \%, \Delta R_{r}=+100 \%$, and $\Delta M=-50 \%$.

6.1. Drive Dynamics without Parameters Estimation. The drive has been subjected to the following speed and torque profiles:

(i) The speed increases from $0 \mathrm{~s}$ to $1 \mathrm{~s}$ to reach the nominal speed $\Omega_{m}=1500 \mathrm{rpm}$ at which the reference is maintained constant.

(ii) Then the speed will be stabilized at $\Omega_{m}=1500 \mathrm{rpm}$ from $1 \mathrm{~s}$ to $1.5 \mathrm{~s}$. (iii) After that, a linear and rapid decrease of the speed to $\Omega_{m}=750 \mathrm{rpm}$ from $1.5 \mathrm{~s}$ to $1.8 \mathrm{~s}$.

(iv) Finally, the speed will be stabilized at $\Omega_{m}=750 \mathrm{rpm}$ from $1.8 \mathrm{~s}$ until $2 \mathrm{~s}$.

Figure 4 shows simulation results corresponding to startup operation of the induction motor under the VSC-DTCSVM approach without parameter variations. It is obvious that the speed reaches its desired trajectory, and the flux remains constant. The ondulations of the electromagnetic 


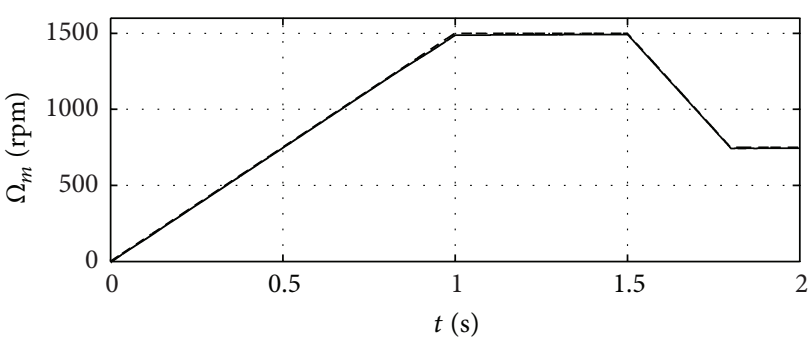

(a)

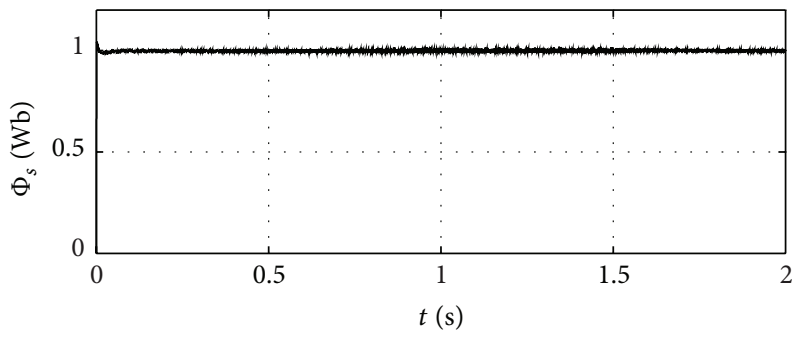

(c)

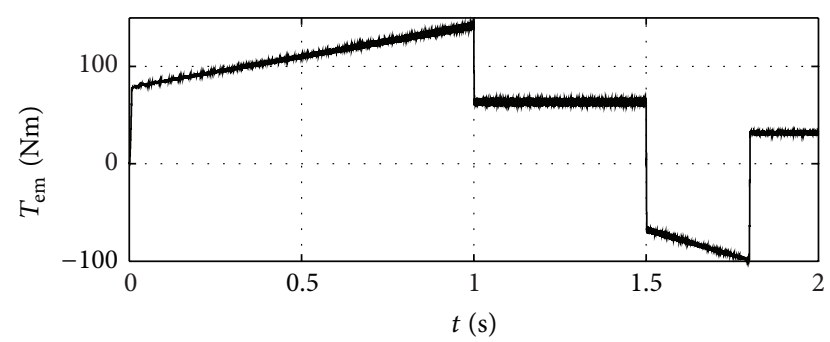

(b)

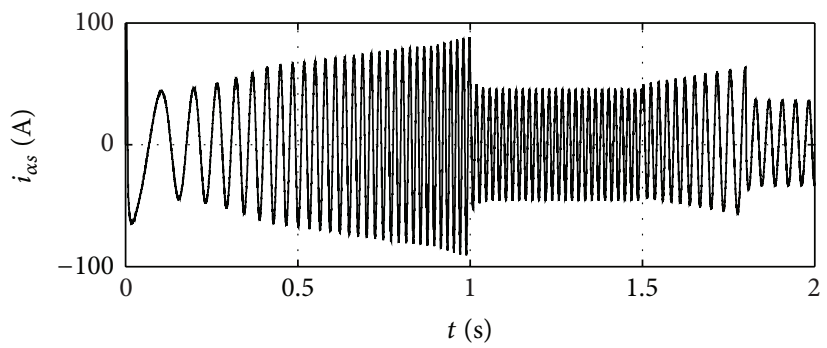

(d)

FIGURE 6: Transient behavior of the induction motor under DTC-SVM using sliding mode controllers with parameters estimation, with parameters variations $\Delta R_{s}=+100 \%$ and $\Delta M=-50 \%$.

torque are also reasonable, and variations of currents phase have interesting shapes. It is notable that the amplitude of the current increases for the acceleration and the deceleration phases.

Figure 5 shows simulation results corresponding to startup operation of the induction motor under the VSC-DTCSVM approach with the following parameter variations $\Delta R_{s}=+100 \%, \Delta R_{r}=+100 \%$, and $\Delta M=-50 \%$. We apply

(i) a linear decrease on the mutual inductance applied starting from $0.2 \mathrm{~s}$ to $0.4 \mathrm{~s}$,

(ii) a linear increase of the rotor resistance from $0.5 \mathrm{~s}$ to $0.7 \mathrm{~s}$,

(iii) and a linear increase of the stator resistance from $1.3 \mathrm{~s}$ to $1.4 \mathrm{~s}$.

We have chosen these sequences based on the fact that the machine will be saturated while currents increase, and much later, machine windings heat up causing an increase of the rotor and the stator resistances. Without updating values of the mutual inductance and the stator resistance in the control laws, performances have been degraded. In fact, the speed cannot follow its desired trajectory having a static error. Moreover, when the speed reaches $1000 \mathrm{rpm}$, the flux becomes larger than its desired value, causing higher ripples of the electromagnetic torque.

6.2. Drive Dynamics with Parameters Estimation. Computer simulations have been performed to determine the observer sensitivity to motor parameters changes. We have considered the stator resistance, the rotor resistance, and the mutual inductance which take shapes described above.
Figure 6 shows simulation results corresponding to startup operation of the induction motor under the VSC-DTCSVM approach with parameter variations and with updates of estimations of the stator resistance, the rotor resistance and of the mutual inductance. It is well obvious that obtained results have been improved, and the degraded performances have been corrected.

The obtained results can be illustrated as

(i) Referring to Figures 4(a) and 6(a), VSC-DTC-SVM approach without parameter variations and VSCDTC-SVM approach with adaptive parameter estimation exhibit almost the same speed dynamics, especially in steady state operation.

(ii) Referring to Figures 5(a), 5(b), and 5(c), it is to be noted that the speed, the electromagnetic torque, and the stator flux do not follow their references. This deviation is due to parameter variations.

(iii) Referring to Figures 4(c) and 6(c), one can notice a remarkable current peak during the start-up in results obtained by VSC-DTC-SVM system without parameter variations and the one with adaptive parameter estimation.

(iv) The curves relating to VSC-DTC-SVM approach, with the adaptive estimators show the effectiveness of the proposed controllers. These curves prove the robustness of the proposed parameter estimators in the case of parametric variations.

(v) Figure 7 describes the evolution of estimated parameters. It is obvious that the stator resistance, the rotor resistance, and the mutual inductance follow their actual values. This explains the improvement of results of Figure 6 (with parameter estimators) 




(a)

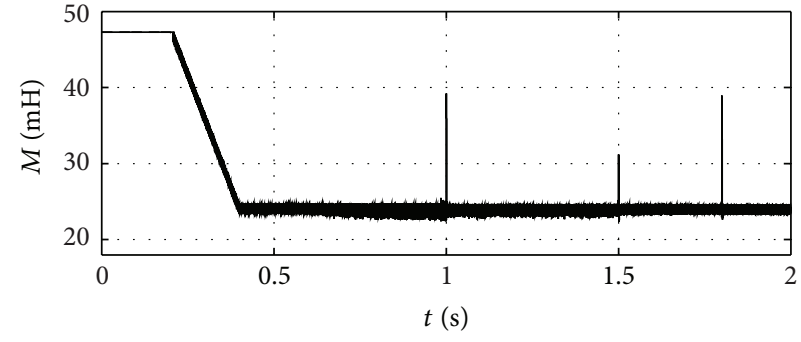

(b)

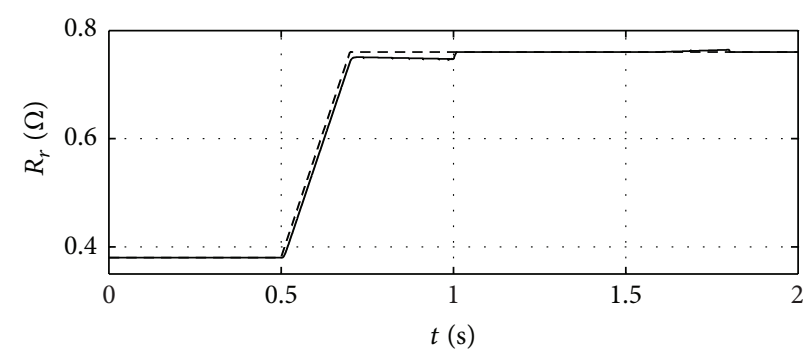

(c)

FIGURE 7: Evolution of estimated stator resistance $R_{s}$ and mutual inductance $M$ of the induction motor under DTC-SVM using sliding mode controllers with parameters estimation, with parameters variations $\Delta R_{s}=+100 \%, \Delta R_{r}=+100 \%$, and $\Delta M=-50 \%$.

compared to ones of Figure 5 (without parameter estimators).

(vi) Figure 7(c) shows that the estimation of the mutual inductance undergos sudden variations (impulse variations) each time when the slope of the speed undergos any variation (at times $1 \mathrm{~s}, 1.5 \mathrm{~s}$, and $1.8 \mathrm{~s}$ ), that is, when the torque undergos a sudden variation.

(vii) In order to have real estimations of the stator and rotor resistances and the mutual inductances, we have added a saturation function on these estimations. In fact, stator resistance and rotor resistance cannot be less than their values at cold. Moreover, they have no meaning if they become larger than three times of these values. However, the mutual inductance cannot be larger than its value at rest, and its value has no meaning if it becomes smaller than the quarter of its value at rest. Then we have:

$$
\begin{aligned}
& R_{s o} \leq \bar{R}_{s} \leq 3 R_{s o}, \\
& R_{r o} \leq \bar{R}_{r} \leq 3 R_{r o}, \\
& \frac{1}{4} M_{o} \leq \bar{M} \leq M_{o},
\end{aligned}
$$

where $R_{s o}, R_{r o}$, and $M_{o}$ are values at rest of the stator resistance, the rotor, and the mutual inductance, respectively.

\section{Conclusion}

The present work has been dedicated to the study of a framework unifying direct torque control space vector modulation (DTC-SVM) and variable structure control (VSC). The result, which is a hybrid VSC-DTC-SVM controller design, eliminates limitations of the two individual controls. It retains merits of both controllers.

Moreover, The present paper has been devoted to the analysis of effects of the stator resistance, the rotor resistance, and the mutual inductance variations on the performances of the VSC-DTC-SVM induction motor drive system. Based on Lyapunov theory, on line estimations of these parameters have been carried out to improve performances of the proposed approach. Regarding the induction motor, simulation results dealing with performances of the adaptive VSC-DTCSVM approach dedicated to speed drives have been presented and discussed.

The presented work can be easily applied to stochastic systems. In fact, sliding mode control is insensitive to external disturbances. However, the application of this work can be extended to other classes of complex systems, such as time delay systems, hybrid systems, and so forth.

\section{Conflict of Interests}

The authors declare that there is no conflict of interests regarding the publication of this paper.

\section{References}

[1] I. Takahashi and T. Noguchi, "A new quick-response and high-efficiency control strategy of an induction motor," IEEE Transactions on Industry Applications, vol. IA-22, no. 5, pp. 820827, 1986.

[2] M. Depenbrock, U. Baader, and G. Gierse, "Direct Self-Control (DSC) of inverter-fed induction machine: a basis for speed control without speed measurement," IEEE Transactions on Power Electronics, vol. 3, no. 4, pp. 420-429, 1988. 
[3] F. Ben Salem, A. Yangui, and A. Masmoudi, "On the reduction of the commutation frequency in DTC: a comparative study," European Transactions on Electrical Power Engineering, vol. 15, no. 6, pp. 571-584, 2005.

[4] P. Brandstetter, P. Chlebis, and P. Palacky, "Direct torque control of induction motor with direct calculation of voltage vector," Advances in Electrical and Computer Engineering, vol. 10, no. 4, pp. 17-22, 2010.

[5] H. Chaikhy, M. Khafallah, and A. Saad, "Evaluation of two control strategies for induction machine," International Journal of Computer Applications, vol. 35, no. 5, pp. 571-584, 2011.

[6] R. Sadouni and A. Meroufel, "Performances comparative study of field oriented control (FOC) and direct torque control (DTC) of dual three phase induction motor (DTPIM)," International Journal of Circuits, Systems and Signal Processing, vol. 6, no. 2, pp. 163-170, 2012.

[7] S. Allirani and V. Jagannathan, "Direct torque control technique in induction motor drives-a review," Journal of Theoretical and Applied Information Technology, vol. 60, no. 3, pp. 454-475, 2014.

[8] N. R. N. Idris and A. H. M. Yatim, "Reduced torque ripple and constant torque switching frequency strategy for direct torque control of induction machine," in Proceedings of the 15th Annual IEEE Applied Power Electronics Conference and Exposition (APEC '00), pp. 154-161, New Orleans, La, USA, February 2000.

[9] W. Srirattanawichaikul, Y. Kumsuwan, and S. Premrudeepreechacharn, "Reduction of torque ripple in direct torque control for induction motor drives using decoupled amplitude and angle of stator flux control," ECTI Transactions on Electrical Engineering, Electronics, and Communications, vol. 8, no. 2, pp. 187-196, 2010.

[10] K. K. Shyu, J. K. Lin, V. T. Pham, M. J. Yang, and T. W. Wang, "Global minimum torque ripple design for direct torque control of induction motor drives," IEEE Transactions on Industrial Electronics, vol. 57, no. 9, pp. 3148-3156, 2010.

[11] F. Ben Salem and A. Masmoudi, "A comprehensive analysis of the inverter switching frequency in Takahashi DTC strategy," The International Journal for Computation and Mathematics in Electrical and Electronic Engineering, vol. 26, no. 1, pp. 148-166, 2007.

[12] R. Zaimeddine and E. M. Berkouk, "Enhanced direct torque control using a three-level voltage source inverter," Asian Power Electronics Journal, vol. 1, no. 1, pp. 64-68, 2007.

[13] N. A. Azli, N. M. Nordin, and N. R. N. Idris, "Direct torque control of multilevel inverterfed induction machines-a survey," Journal of Theoretical and Applied Information Technology, vol. 41, no. 2, pp. 181-191, 2012.

[14] C. H. Krishna, J. Amarnath, and S. Kamakshiah, "A simplified SVPWM algorithm for multi-level inverter fed DTC of induction motor drive," International Journal of Engineering and Innovative Technology, vol. 1, no. 4, pp. 61-67, 2012.

[15] T. G. Habetler, F. Profumo, M. Pastorelli, and L. M. Tolbert, "Direct torque control of induction machines using space vector modulation," IEEE Transactions on Industry Applications, vol. 28, no. 5, pp. 1045-1053, 1992.

[16] C. Y. Chen, "Sliding mode controller design of induction motor based on space-vector pulsewidth modulation method," International Journal of Innovative Computing, Information and Control, vol. 5, no. 10, pp. 3603-3614, 2009.

[17] A. Joseline Metilda, R. Arunadevi, N. Ramesh, and C. Sharmeela, "Analysis of direct torque control using space vector modulation for three phase induction motor," Recent Research in Science and Technology, vol. 3, no. 7, pp. 37-40, 2011.

[18] H. F. Rashag, S. P. Koh, K. H. Chong, S. K. Tiong, N. M. L. Tan, and A. N. Abdalla, "High performance of space vector modulation direct torque control SVM-DTC based on amplitude voltage and stator flux angle," Research Journal of Applied Sciences, Engineering and Technology, vol. 5, no. 15, pp. 3934-3940, 2013.

[19] A. Ouarda and F. Ben Salem, "Induction machine DTC-SVM: A comparison between two approaches," in Proceedings of the 10th International Multi-Conference on Systems, Signals and Devices (SSD '13), March 2013.

[20] N. Ahammad, S. A. Khan, and R. K. Reddy, "Novel DTC-SVM for an adjustable speed sensorless induction motor drive," International Journal of Science Engineering and Advance Technology, vol. 2, no. 1, pp. 31-36, 2014.

[21] M. S. Carmeli and M. Mauri, "Direct torque control as variable structure control: existence conditions verification and analysis," Electric Power Systems Research, vol. 81, no. 6, pp. 1188-1196, 2011.

[22] D. Veera and T. B. Reddy, "Implementation of discrete space vector modulation based direct torque control of induction motor for reduced ripple: a sliding mode control approach," International Journal of Advanced Scientific and Technical Research, vol. 4, pp. 22-38, 2012.

[23] F. Ben Salem and N. Derbel, "Direct torque control of induction motors based on discrete space vector modulation using adaptive sliding mode control," International Journal of Electric Power Components and Systems, vol. 42, no. 13-16, 2014.

[24] F. B. Salem and N. Derbel, "A sliding mode field oriented control of an induction machine operating with variable parameters," International Journal of Power and Energy Systems, vol. 27, no. 2, pp. 205-212, 2007.

[25] K. Venkateswarlu, G. Sandeep, N. Srinivas, and K. Damodara Reddy, "Speed sensorless sliding mode control of induction motor using simulink," IOSR Journal of Electrical and Electronics Engineering, vol. 6, no. 2, pp. 50-56, 2013.

[26] Y. Chang and C. Wen, "Sliding mode control for the synchronous generator," ISRN Applied Mathematics, vol. 2014, Article ID 256504, 7 pages, 2014.

[27] S. Mir, M. E. Elbuluk, and D. S. Zinger, "PI and fuzzy estimators for tuning the stator resistance in direct torque control of induction machines," IEEE Transactions on Power Electronics, vol. 13, no. 2, pp. 279-287, 1998.

[28] F. Zidani and D. Diallo, "Direct torque control of induction motor with fuzzy stator resistance adaptation," IEEE Transactions on Energy Conversion, vol. 21, no. 2, pp. 619-621, 2006.

[29] B. M. Chandra and S. T. Kalyani, "FPGA controlled stator resistance estimation in IVC of IM using FLC," Global Journal of Researches in Engineering Electrical and Electronics Engineering, vol. 13, no. 13, 2013.

[30] L. Wu, X. Su, and P. Shi, "Output feedback control of Markovian jump repeated scalar nonlinear systems," IEEE Transactions on Automatic Control, vol. 59, no. 1, pp. 199-204, 2014.

[31] F. Li, P. Shi, L. Wu, and X. Zhang, "Fuzzy-model-based Dstability and non-fragile control for discrete-time descriptor systems with multiple delays," IEEE Transactions on Fuzzy Systems, vol. 22, no. 4, pp. 1019-1025, 2013.

[32] F. Li, L. Wu, and P. Shi, "Stochastic stability of semi-Markovian jump systems with mode-dependent delays," International Journal of Robust and Nonlinear Control, 2013. 
[33] F. Li and X. Zhang, "A delay-dependent bounded real lemma for singular LPV systems with time-variant delay," International Journal of Robust and Nonlinear Control, vol. 22, no. 5, pp. 559574, 2012.

[34] H. F. Rashag, N. M. L. Tan, S. P. Koh, A. N. Abdalla, K. H. Chong, and S. K. Tiong, "DTC-SVM based on PI torque and PI flux controllers to achieve high performance of induction motor," Research Journal of Applied Sciences, Engineering and Technology, vol. 7, no. 4, pp. 875-891, 2014.

[35] F. Ben Salem and N. Derbel, "VSC-based DTC-SVM with adaptive parameter estimation," in Proceedings of the 11th International Multi-Conference on Systems, Signals \& Devices (SSD '14), pp. 1-7, Barcelona, Spain, February 2014.

[36] Z. Yan, C. Jin, and V. I. Utkin, "Sensorless sliding-mode control of induction motors," IEEE Transactions on Industrial Electronics, vol. 47, no. 6, pp. 1286-1297, 2000.

[37] K. D. Young, V. I. Utkin, and Ü. Özgüner, "A control engineer's guide to sliding mode control," IEEE Transactions on Control Systems Technology, vol. 7, no. 3, pp. 328-342, 1999.

[38] A. G. Loukianov, "Robust block decomposition sliding mode control design," Mathematical Problems in Engineering, vol. 8, no. 4-5, pp. 349-365, 2002.

[39] V. I. Utkin, "Sliding mode control design principles and applications to electric drives," IEEE Transactions on Industrial Electronics, vol. 40, no. 1, pp. 23-36, 1993.

[40] A. Jidin, N. R. N. Idris, and A. H. M. Yatim, "Study on stability and performances of DTC due to stator resistance variation," in Proceedings of the 5th Student Conference on Research and Development (SCORED '07), pp. 1-6, Selangor, Malaysia, December 2007.

[41] "IEEE Standard Test Procedure for Polyphase Induction Motors and Generators," IEEE Std 112-1991, IEEE, 1991. 


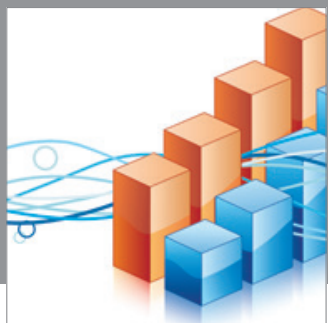

Advances in

Operations Research

mansans

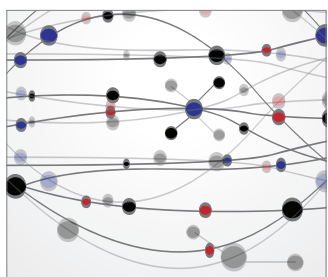

The Scientific World Journal
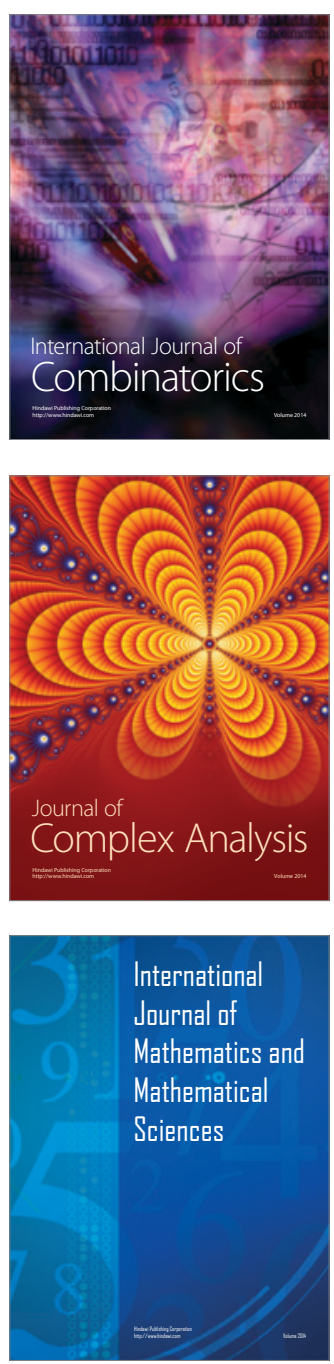
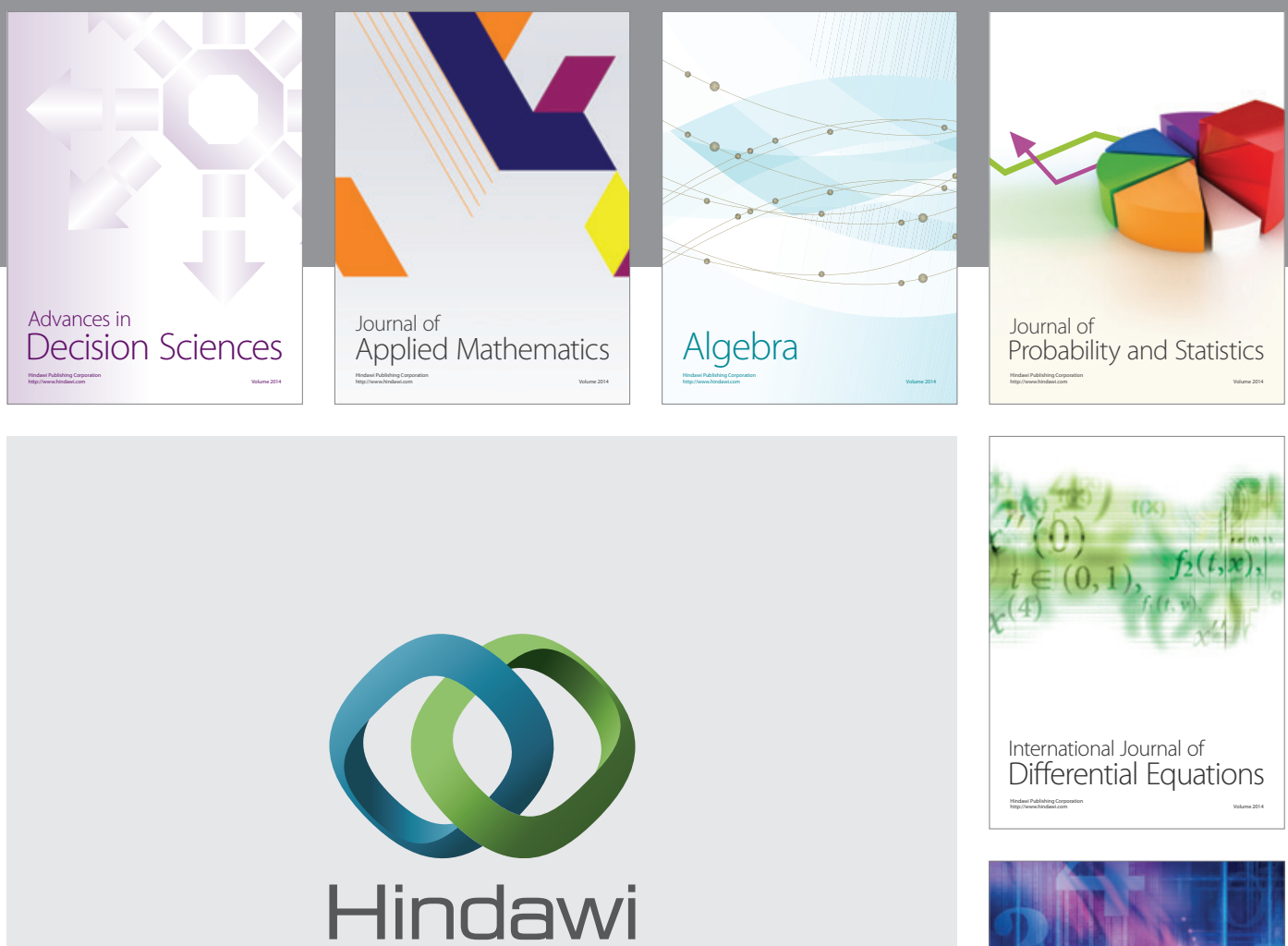

Submit your manuscripts at http://www.hindawi.com
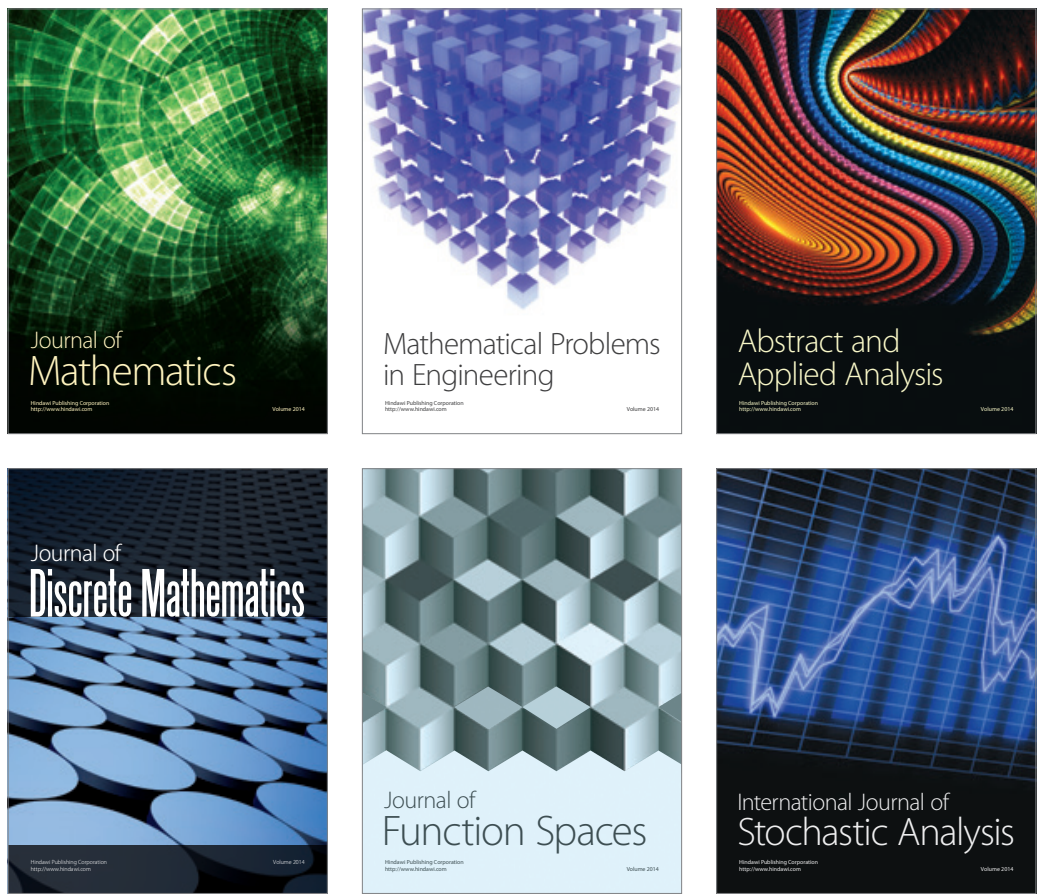

Journal of

Function Spaces



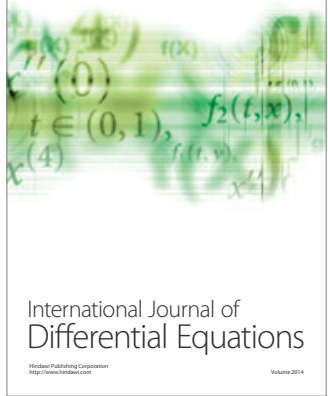
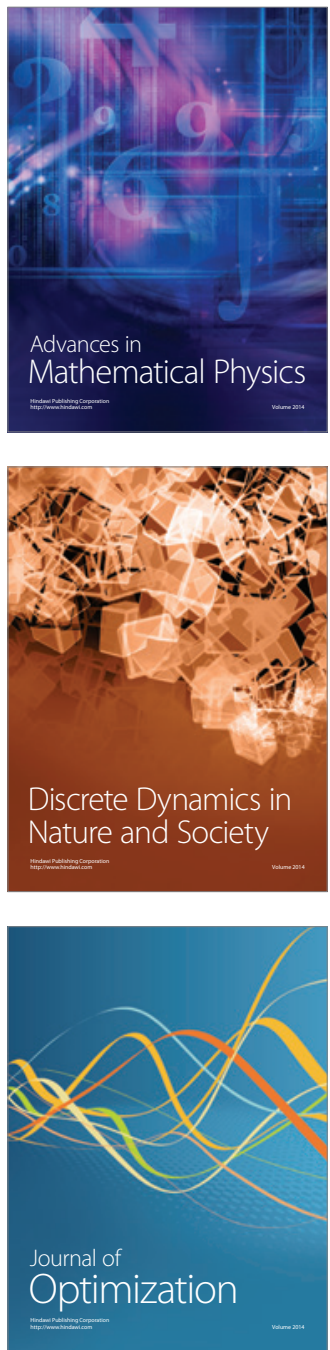